\title{
Intellectual Property Protection of Biological Genetic Resources
}

\author{
Yayun Luo* \\ Department of Law, School of Law, Humanities and Sociology, Wuhan University of Technology, Wuhan, Hubei, \\ China \\ *Corresponding author. Email:1102150355@qq.com
}

\begin{abstract}
There is a serious loss of biological genetic resources in China, the domestic legislation on biological genetic resources is scarce and scattered, so we should improve the domestic law of biological genetic resources as soon as possible. Research from the aspects of intellectual property rights (ipr) protection, summarized at home and abroad on biological genetic resources protection way, the intellectual property system in China were analyzed, and the biological genetic resources protection Suggestions and countermeasures, which improve the biological genetic resources in the patent law and perfect the relevant provisions of the biological genetic resources access and benefit sharing mechanism.
\end{abstract}

Keywords: Biological genetic resources, Intellectual property rights, Protection, Access and benefit sharing.

\section{INTRODUCTION}

Currently, we can observe that biological genetic resources are constantly disappearing. Faced with this issue, the international community has begun to pay attention to the protection of biological genetic resources, and countries have successively signed relevant international treaties and introduced relevant domestic laws. As one of the countries with the richest biological genetic resources in the world, China is plundered by other countries with superb biotechnology. China suffers from "biological plagiarism". For example, the Swiss Roche company uses our country's tradition as a spice and anti-inflammatory town. The star anise of the pain and cold medicine, and Tamiflu, which is extracted from shikimic acid for the prevention and treatment of influenza, has obtained huge benefits after applying for a patent. This reflects my country's important issue of the lack of intellectual property rights of biological genetic resources. Therefore, in such a complicated international background, it is urgent to analyze how to use intellectual property rights to protect the characteristics of biological genetic resources.

\section{BASIC UNDERSTANDING OF THE RELATIONSHIP BETWEEN BIOLOGICAL GENETIC RESOURCES AND INTELLECTUAL PROPERTY}

Bio-genetic resources are a country's strategic resources, which have significant economic value in medicine, food, industry, etc. Biological genetic resources have their own specific four characteristics, which are compounders, non-renewability, imbalance and potential value, which can bring huge benefits to mankind.[1]My country is a large country with rich biological genetic resources, there is a serious phenomenon of "biological plagiarism", and the loss of biological genetic resources is serious. Genetic resources are a kind of original composition. Strengthening the protection of genetic resources and their intellectual property rights from the intellectual property strategy level is the fundamental connotation of ecological civilization. Studying protection countermeasures as soon as possible to deal with the reality of rapid disappearance of genetic resources has become a fundamental issue in the development of national and regional strategies that cannot be avoided.[2]Intellectual property rights carry the important role of protecting biological genetic resources from being stolen by other countries and promoting the 
access and benefit sharing of biological genetic resources. It is a rigid demand for the sustainable use of biological genetic resources. In the era of biotechnology, strong intellectual property protection is needed to encourage the biotechnology industry to engage in arduous research and development activities. The generation and creation of benefits is a prerequisite for sharing. Only operations based on intellectual property rights can ultimately achieve benefits and sharing.[3]

\section{THE BASIC SITUATION OF INTELLECTUAL PROPERTY PROTECTION OF BIOLOGICAL GENETIC RESOURCES AT HOME AND ABROAD}

\subsection{Status of International Protection}

Regarding the protection of genetic resources, the most important and authoritative convention in the world is the Convention on Biological Diversity (hereinafter referred to as CBD) adopted at the United Nations Conference on Environment and Development held in Rio de Janeiro, Brazil in 1992. The convention was concluded at the end of 1993. Effective, my country joined in $1993 .{ }^{[4]}$ This is a legally binding international convention. The CBD aims to protect biological resources and genetic resources, while also protecting this accompanying traditional knowledge and ensuring fair sharing of benefits arising from the use of biological resources and related traditional knowledge. ${ }^{[5]}$ One of the goals of CBD is to equitably and reasonably share the benefits brought about through biological genetic resources, use the reasonable acquisition of biological genetic resources and the transfer of related technology and methods, to maximize the protection of rights holders, and at the same time Obtain certain financial support.[6]

In October 2010, the United Nations passed the historic "Convention on Biological Diversity's Nagoya Protocol on Access to Genetic Resources and Fair and Equitable Sharing of Benefits from Their Utilization." A few days ago, many countries such as India, Australia, Brazil, etc. have passed their own legislation to ensure the effective implementation of the "Nagoya Protocol" in the country to protect their own biological genetic resources.[7]

\subsection{Status of Domestic Protection}

After the United Nations Conference on Environment and Development in 1992, China, taking into account its national conditions, acceded to the Convention on Biological Diversity and formally acceded to the Nagoya Protocol in September 2016. In the past 28 years, China has paid more and more attention to the protection of biological genetic resources, and formulated and revised many domestic laws in order to achieve the purpose of protecting biological genetic resources. In the relevant legislation, there is no comprehensive protection for the whole biological genetic resources, and there are many separate legislations for the protection of genetic resources in individual fields such as animals and plants, but undoubtedly, they all play a positive role in strengthening the management of biological genetic resources and controlling the loss of biological genetic resources.

In view of the protection and management requirements of genetic resources, the State issued the Outline of the National Plan for The Protection and Utilization of Biological Species Resources in 2007 and formulated the Outline of the National Intellectual Property Strategy in 2008. These policy documents confirmed and recognized the important status of genetic resources protection from the perspective of policies. In 2013, the State Council decided to revise the Regulations of the People's Republic of China on the Protection of New Plant Varieties to strengthen the protection of new plant varieties. Then, the revised Seed Law of the People's Republic of China in 2015 provided detailed provisions on the content of new plant variety rights, the acquisition of resources and the benefit sharing procedures, which solved the problems such as vague content provisions before the regulation. In 2014, China published the Notice on Strengthening the Utilization and Benefit-sharing Management of Biological Genetic Resources in Foreign Cooperation and Exchange, which emphasized the importance of strengthening the protection and management of biological genetic resources and further regulated the acquisition and benefit-sharing of genetic resources in foreign cooperation and exchange activities.

\section{THE PROTECTION MODE OF MY COUNTRY'S INTELLECTUAL PROPERTY SYSTEM ON BIOLOGICAL GENETIC RESOURCES}

\subsection{Patent System Protection}

The current "Patent Law of the People's Republic of China" (hereinafter referred to as "Patent Law") Article 26, paragraph 6 stipulates: "For inventions and creations that rely on genetic resources, the applicant shall state the directness of the genetic resources in the patent application documents. Source and original source; if the applicant is unable to explain the original source, it shall state the reasons.". Article 26 of the "Detailed Regulations for the Implementation of the Patent Law of the People's Republic of China" specifies the scope of protected biological genetic resources in detail. However, in the application process, if the biological 
genetic resources are passed down from generation to generation, the identification of the applicant becomes a problem. The second problem is that when using the Patent Law for protection, we must consider the issue of coverage. If we want to truly protect a biological genetic resource from being stolen by other countries, then the biological genetic resource itself and all the inventions that rely on its Creation must be granted a patent. The third question is that if the patent applicant is unable to explain the original source or cannot disclose the original source for some reason, then the protection of biological genetic resources will be shelved. Therefore, it is difficult to use the Patent Law to comprehensively protect biological genetic resources.

\subsection{Geographical Indication Protection}

In terms of protection subjects, geographical indications are similar to biological genetic resources. The subject of geographical indication rights is a collective common right ${ }^{[8]}$, and most protection subjects of biological genetic resources also belong to the collective. In the sense of origin, the owners of biological genetic resources can obtain benefits through the application of geographical indications, because the owners of biological genetic resources have the right to require users of geographical indications to pay appropriate fees or remuneration.

However, a geographical indication is a sign that links the quality, reputation or other characteristics of a product with the place of origin. This sign makes the product more distinctive, economic value and property benefits. For biological genetic resources, the place of origin only serves as a proof. Its value is not produced by the place of origin, but by its genetic information. Therefore, the protection of biological genetic resources by geographical indications is limited.

\subsection{Protection of New Plant Variety Rights}

At present, my country began to implement the "Regulations on the Protection of New Plant Varieties of the People's Republic of China" in 1997 and the "Seed Law of the People's Republic of China" in 2016. The new plant variety right protects the new plant variety itself. It grants the owner of the new plant variety the exclusive right to its new plant variety for a certain period of time. Any other unit or individual has not obtained the authorization of the new plant variety right owner. The new plant variety cannot be used commercially, nor can it be commercialized to produce another new variety.

New plant varieties protection of new plant varieties is itself, which gives the holder of the new plant varieties of new plant varieties in a certain period of it shall enjoy the right of exclusive monopoly, any other unit or individual without authorization, new plant varieties and not commercial use of new plant varieties, also not commercially to produce another new variety. New plant variety rights are regional and only valid in the country in which they are acquired. New varieties of plants are also time-sensitive and can be freely used by anyone after the expiry of their effective protection. Thus, it can be seen that the scope and strength of new plant variety right protection are small.

\subsection{Protection of Trade Secrets}

Article 9 of the Anti-Unfair Competition Law of the People's Republic of China stipulates the protection of trade secrets and trade secrets. The protected objects are information, that is, information that is confidential, beneficial and practical to the right holder. information. Bio-genetic resources are information with economic value, so it is a good way to protect bio-genetic resources by using trade secret rights. In biological genetic resources, medical knowledge that has been passed down from generation to generation and is not known to outsiders conforms to the characteristics of secrecy. If the use of such medical knowledge can bring economic value to the right holder and it has practicality to effectively solve the disease, then such genetic resources can be protected through trade secret rights.

However, not all biological genetic resources can be protected by the right to trade secrets, and some agricultural genetic resources cannot be protected either, because traditional agricultural cultivation and domestication of livestock are open, and the agricultural USES of these animals and plants can be easily known from their appearance and shape. In addition, although the right holder of the right of trade secret can have the right to keep the secret permanently and does not need to file an application and spend a certain amount of money to maintain the right like the patent right, the protection effect of the right of trade secret is weaker than that of the patent right. Because a patent can disclose a technology, then prohibit others from using reverse engineering or even independently developed the same technology, also cannot commercially exploit the technology invention; however, the right to trade secrets cannot prohibit others from making the same technological invention and development. In fact, after others have completed the same technology through reverse engineering or independent development and applied for patent protection, they can even reversely forbid the holders of trade secrets from further commercial use of the technology.[9] 


\section{COUNTERMEASURES AND SUGGESTIONS FOR INTELLECTUAL PROPERTY PROTECTION OF BIOLOGICAL GENETIC RESOURCES}

\subsection{Improve the Relevant Regulations on Biological Genetic Resources in the Patent Law}

Regarding the problem that the source of biological genetic resources cannot be explained, the situation where the original source is really unclear should be considered, and the revision should be made in detail from the perspective of individuals, enterprises or institutions. For cases where the patent applicant knows the original source but is unwilling to disclose it, specific regulations can be adopted. The enumeration method can be used to list common reasons that can be accepted by the examination department, such as state secrets or trade secrets.

\subsection{Improve the Access and Benefit Sharing Mechanism of Biological Genetic Resources}

CBD believes that the protection of biological genetic resources must be reflected in the benefitsharing regulations. ${ }^{[10]}$ In the future, if my country wants to establish the core content of the legislation on the access and benefit sharing of genetic resources, it should include clarifying the purpose of the legislation, clarifying the principles of the legislation, including the bio-genetic resources in the scope of the material applicable to the legislation, and establishing complete access procedures. And the establishment of a remedy system for violation of prior informed consent procedures.[11]

\section{CONCLUSION}

In recent years, in order to prevent the loss of biological genetic resources, and at the same time the economic value of biological genetic resources is gradually recognized and valued, international and national governments are actively working towards establishing reasonable and standardized biological genetic resources laws. When exploring how to use intellectual property rights to protect biological heritage resources, in addition to studying foreign legislation related to biological genetic resources under the system provided by international documents, it also put forward countermeasures and suggestions based on my country's specific national conditions and current legislation. In the current environment where there are many shortcomings in the protection of biological genetic resources in our country, the biological genetic resources and the intellectual property system's trade secret rights, patent rights, plant variety rights, and geographical indications are integrated and analyzed, and our country is analyzed The existing shortcomings in the protection of biological genetic resources have put forward some countermeasures and suggestions for the intellectual property protection of biological genetic resources in my country in the future. However, under the current circumstances, although the protecti on of biological genetic resources is an inevitable choice, due to the involvement of biological genetic resources, technology, and public order, further research and improvement are needed.

\section{REFERENCES}

[1] Tobin B. Biopiracy by Law: European Union Draft Law Threatens Indigenous Peoples' Rights over their Traditional Knowledge and Genetic Resources[J]. European Intellectual Property Review, 2014, 36(2):124.

[2] $\mathrm{Wu}$ Handong. Protecting the intellectual property rights of genetic resources is the proposition of the times[N]. Chinese Journal of Science, 2017-0526(006).

[3] Xu Shan.Thoughts on the domestic legal regulation of biopiracy[J]. Environmental Protection and Circular Economy,2015,35(02):4-9.

[4] Xiao Ting.On the legal protection of genetic resources[J]. Journal of Shaoguan University,2010,31(08):45-48.

[5] Xue da-yuan, guo luo-lu. On the concept and protection of traditional knowledge [J] Biodiversity,2009,17(02):135-142.

[6] Research on intellectual Property Protection of Biological Genetic Resources [D]. Northeast Forestry University,2016.

[7] $\mathrm{Wu}$ Jianyong. The protection of intellectual property related to biological genetic resources and traditional knowledge in China urgently needs to be strengthened $[\mathrm{J}]$. World Environment,2016(S1):1618.

[8] Zhao Chunyi. Deficiencies and Improvement of China's Geographical Indication Protection System [D]. Hebei Normal University,2019.

[9] Liu Lin. Preliminary exploration of the intellectual Property Protection Model of biological Genetic Resources [D]. Huazhong University of Science and Technology,2010.

[10] Schei, Peter \& Tvedt, Morten. (2010). 'Genetic Resources' in the CBD The Wording, the Past, the Present and the Future.

[11] Sustainable Development Dimensions. Special: Biodiversity. for Food and Agriculture Soil and Microbial Biodiversity.2013.6:17. 